\title{
HUBUNGAN TINGKAT PENDIDIKAN DENGAN KEIKUTSERTAAN IBU HAMIL DALAM ASUHAN ANTENATAL (ANC) DI PUSKESMAS SOMBA OPU KABUPATEN GOWA TAHUN 2016
}

\author{
Andi Irhamnia Sakinah
}

Fakultas Kedokteran dan Ilmu Kesehatan UIN Alauddin Makassar andi.irhamnia.sakinah@uin-alauddin.ac.id

\begin{abstract}
Abstrak
Penyebab kematian neonatus (2014) yakni masalah gizi buruk dan gizi kurang yang biasanya mulai terjadi sejak masa kehamilan. Kabupaten Gowa menempati urutan tertinggi dalam jumlah kematian ibu hamil di Provinsi Sulawesi Selatan tahun 2013. Kematian maternal dapat dicegah melalui asuhan antenatal (ANC). Motivasi ibu hamil datang mengikuti ANC di fasilitas kesehatan dapat dipengaruhi oleh berbagai faktor. Penelitian ini bertujuan untuk menganalisa hubungan tingkat pendidikan ibu hamil dengan keikutsertaannya dalam ANC di Puskesmas Somba Opu Kabupaten Gowa. Penelitian survei deskriptif analitik ini mengggunakan rancangan cross sectional study dengan responden ibu hamil yang berkunjung di Puskesmas Somba Opu pada 27 Oktober s.d. 7 Oktober 2016 dengan accidental sampling. Data diuji secara statistik menggunakan uji chi square. Terdapat hubungan antara tingkat pendidikan dengan keikutsertaan ibu hamil dalam asuhan antenatal (anc) di Puskesmas Somba Opu Kabupaten Gowa tahun 2016, yakni tingkat pendidikan yang cukup berhubungan $(\mathrm{p}=0.037)$ dengan kesesuaian kunjungan asuhan antenatal (ANC) dengan kekuatan hubungan lemah $(\varphi=0,247)$. Kata Kunci: tingkat pendidikan, ibu hamil, asuhan antenatal/ ANC
\end{abstract}

\section{PENDAHULUAN}

Angka kematian maternal di dunia masihlah sangat tinggi. Sekitar 830 perempuan meninggal akibat komplikasi terkait kehamilan dan kelahiran di seluruh dunia setiap harinya. Hampir seluruh kematian ini terjadi pada daerah dengan sumber daya rendah, dan kebanyakan dapat dicegah, salah satunya solusi pelayanan kesehatan untuk mencegah atau mengelola komplikasi yang telah diketahui. ${ }^{1}$

Saat ini Indonesia masih menghadapi masalah tingginya angka kematian bayi. Berdasarkan data angka kematian neonatal, bayi dan balita di Indonesia, sekitar $56 \%$ kematian bayi terjadi pada masa neonatal dan salah satu penyebabnya yakni gizi buruk dan gizi kurang yang biasanya mulai terjadi sejak masa kehamilan. ${ }^{2}$ Angka kematian bayi baru lahir pada anak-anak yang ibunya mendapatkan pelayanan antenatal dan pertolongan persalinan oleh profesional medis adalah seperlima dari angka kematian pada anak-anak yang ibunya tidak mendapatkan pelayanan ini. ${ }^{3}$

Estimasi angka kematian Ibu di Indonesia tahun 2015 sendiri sebesar 126 per 100.000 kelahiran hidup. ${ }^{1}$ Kabupaten Gowa menempati urutan tertinggi dalam jumlah kematian ibu hamil di Provinsi Sulawesi Selatan tahun 2013. ${ }^{4}$ Tingginya peringkat ini tentunya menggambarkan bahwa tingkat kesadaran perilaku hidup sehat, status gizi dan kesehatan ibu, kondisi kesehatan lingkungan, tingkat pelayanan kesehatan terutama untuk ibu hamil, pelayanan kesehatan waktu ibu melahirkan dan masa nifas masihlah belum cukup baik di masyarakat. Asuhan 
antenatal (ANC) merupakan salah satu upaya penting dalam mengontrol kondisi kesehatan kehamilan Ibu dan janin sehingga dapat mendeteksi apakah terdapat kelainan dalam kehamilan secara dini. Kesehatan ibu hamil tentunya menjadi salah satu faktor yang dapat mempengaruhi angka kematian ibu.

Dalam bahasa program kesehatan ibu dan anak, kunjungan antenatal ini diberi kode angka $\mathrm{K}$ yang merupakan singkatan dari kunjungan dengan kunjungan yang lengkap adalah $\mathrm{K} 1, \mathrm{~K} 2$, K3, dan K4. Artinya, dalam masa kehamilan, minimal dilakukan sekali kunjungan antenatal hingga usia kehamilan 28 minggu, sekali kunjungan selama kehamilan 28-36 minggu, dan sebanyak dua kali kunjungan antenatal pada usia kehamilan di atas 36 minggu. ${ }^{5}$

Data Riskesdas 2013 menunjukkan hampir seluruh ibu hamil di Indonesia $(95,4 \%)$ sudah melakukan pemeriksaan kehamilan (K1) dan frekuensi kunjungan minimal 4 kali selama masa kehamilannya adalah 83,5 persen. Adapun untuk cakupan pemeriksaan kehamilan pertama pada trimester pertama adalah 81,6 persen dan frekuensi ANC 1-1-2 atau K4 (minimal 1 kali pada trimester pertama, minimal 1 kali pada trimester kedua dan minimal 2 kali pada trimester 3) sebesar 70,4 persen. $^{6}$ Kunjungan ANC yang tinggi diharapkan dapat membantu menurunkan komplikasi maternal dan neonatal serta kematian ibu dan anak melalui pendeteksian dini kehamilan berisiko tinggi. ${ }^{7}$

Kebanyakan perempuan hamil (72\%) di Indonesia melakukan kunjungan pertama, tetapi putus sebelum empat kunjungan yang direkomendasikan oleh Kementerian Kesehatan. Kurang lebih $16 \%$ perempuan $(25 \%$ dari pedesaan dan $8 \%$ perempuan perkotaan) tidak pernah mendapatkan pelayanan antenatal selama kehamilan terakhir mereka. ${ }^{3}$

Dari data profil kesehatan Kabupaten Gowa tahun 2014, tampak bahwa cakupan pelayanan K4 selalu lebih rendah daripada cakupan pelayanan K1. Hal ini menunjukkan bahwa mungkin ada suatu faktor yang berperan dalam mempengaruhi motivasi ibu hamil datang mengikuti asuhan antenatal di fasilitas pelayanan kesehatan. Hal ini yang menjadikan alasan perlunya dilakukan penelitian terkait faktor-faktor yang mempengaruhi ibu hamil dalam mengikuti asuhan antenatal di Indonesia, khususnya di Kabupaten Gowa, Sulawesi Selatan.

Siti Candra, dkk (2009) menemukan bahwa pengetahuan berhubungan dengan keteraturan kunjungan antenatal oleh ibu postpartum. Begitu pula dengan hasil penelitian Adri (2008) di Puskesmas Runding Kota Subussalam Provinsi Nanggroe Aceh Darussalam yang menunjukkan bahwa 
variabel pengetahuan mempunyai pengaruh yang positif dan signifikan terhadap pemeriksaan kehamilan. ${ }^{8}$

Selain itu, anak-anak dari ibu yang kurang berpendidikan umumnya memiliki angka kematian yang lebih tinggi daripada mereka yang lahir dari ibu yang lebih berpendidikan. Selama kurun waktu 19982007, angka kematian bayi pada anak-anak dari ibu yang tidak berpendidikan adalah 73 per 1.000 kelahiran hidup, sedangkan angka kematian bayi pada anak-anak dari ibu yang berpendidikan menengah atau lebih tinggi adalah 24 per 1.000 kelahiran hidup. Perbedaan ini disebabkan oleh perilaku dan pengetahuan tentang kesehatan yang lebih baik di antara perempuan-perempuan yang berpendidikan. ${ }^{3}$

\section{METODE PENELITIAN}

Penelitian ini merupakan penelitian survei deskriptif analitik dengan rancangan cross sectional study untuk mengetahui hubungan tingkat pendidikan dengan keikutsertaan ibu hamil dalam asuhan antenatal (ANC) di Puskesmas Somba Opu Kabupaten Gowa tahun 2016. Pengambilan data primer dilakukan dengan menggunakan kuesioner.

Sampel dalam penelitian ini adalah semua populasi yang memenuhi kriteria dijadikan sampel. Pengambilan sampel dilakukan dengan menggunakan teknik accidental sampling. Perhitungan jumlah sampel diperoleh dengan menggunakan Rumus Slovin $(\mathrm{N}=111$ dan $\alpha=5 \%)$ sehingga didapatkan minimal jumlah sampel yang harus didapatkan adalah sebanyak 86 sampel.

Data yang telah dikumpulkan kemudian diolah secara manual dan dengan menggunakan program Microsoft Excel dan SPSS 16.0. Pengujian hipotesis menggunakan uji statistik Chi-Square dengan menggunakan rumus sebagai berikut:

$$
X^{2}=\sum \frac{(O-E)^{2}}{E}
$$

Keterangan :

$$
\begin{aligned}
& \mathrm{X}^{2}=\text { Nilai Chi Square } \\
& \mathrm{O}=\text { Observed (nilai observasi) } \\
& \mathrm{E}=\text { Expected (nilai harapan) } \\
& \text { Untuk mengetahui kuatnya }
\end{aligned}
$$
hubungan jika hasil uji chi-square $\left(\mathrm{X}^{2}\right)$ dan Test Fisher untuk tabel kontingensi 2x2 bermakna digunakan koefisien $\varphi$ (Phi)

$$
\Phi=\frac{|a d-b c|}{\sqrt{(a+b(a+c)(b+d)(c+d)}}
$$

Keterangan:

a. Hubungan lemah $0,01-0,25$

b. Hubungan sedang : 0,26 $-0,5$

c. Hubungan kuat : 0,51 $-0,75$ 
d. Hubungan sangat kuat : 0,76 - 1,00 (Stang, 2005 dalam

Rochka, 2012).

\section{HASIL DAN PEMBAHASAN}

Antenatal Care (ANC) adalah pelayanan kesehatan yang diberikan oleh tenaga kesehatan untuk ibu selama kehamilannya dan dilaksanakan sesuai dengan standar pelayanan yang ditetapkan dalam Standar Pelayanan Kebidanan/SPK. ${ }^{6}$ Bila kehamilan berisiko tinggi perhatian dan jadwal kunjungan harus lebih ketat. Namun, bila kehamilan normal jadwal asuhan cukup empat kali. ${ }^{5}$

Responden yang terpilih sebagai sampel merupakan ibu hamil dengan berbagai usia kehamilan yang sedang melakukan kunjungan antenatal (ANC) di Puskesmas Somba Opu Kabupaten Gowa sejak tanggal 27 Oktober hingga 7 Desember 2016 dengan jumlah responden sebesar 88 orang (Tabel 1.).

Tingkat pendidikan ibu dalam penelitian ini dibagi dalam dua kategori yaitu pendidikan kurang dan cukup. Pendidikan ibu dikatakan kurang jika menyelesaikan pendidikan terakhir maksimal hingga SMP sedangkan pendidikan ibu dikatakan cukup jika mampu menyelesaikan pendidikan terakhir minimal hingga SMA. Menurut tingkat pendidikan terlihat bahwa responden yang memiliki pendidikan cukup yaitu sebanyak 47 orang $(53.4 \%)$ lebih banyak dibandingkan dengan responden yang memiliki pendidikan kurang yaitu sebanyak 41 orang $(46.6 \%)$.

Berdasarkan kesesuaian frekuensi kunjungan ibu hamil untuk ANC selama masa kehamilan pada tiap trimester, kunjungan asuhan antenatal dibagi dalam 2 kategori yaitu tidak sesuai standar dan sesuai standar. Kunjungan ANC sesuai standar bila kunjungan dilakukan minimal 1 kali pada trimester I, 1 kali pada trimester II, dan 2 kali pada trimester III.

Secara umum, ditemukan bahwa kunjungan asuhan antenatal yang sesuai standar di Puskesmas Somba Opu tergolong cukup tinggi. Hal ini tampak dari 88 responden yang diteliti, terdapat 60 orang $(68.2 \%)$ yang mengikuti asuhan antenatal sesuai standar dan 28 orang (31.8\%) yang mengikuti asuhan antenatal tidak sesuai standar. Artinya, terdapat $68.2 \%$ responden yang kunjungan antenatalnya sudah sesuai dengan standar asuhan antenatal yang ditetapkan.

Meskipun jumlah ibu hamil yang mengikuti asuhan antenatal di Puskesmas Somba Opu lebih banyak yang melakukan sesuai standar, namun masih terdapat $31.8 \%$ ibu yang mengikuti kunjungan tidak sesuai standar. Dari hasil wawancara langsung oleh peneliti dengan responden selama proses pengambilan data, didapatkan bahwa penyebab beberapa responden tidak mengikuti kunjungan 
asuhan antenatal sesuai standar oleh karena ketidaktahuan responden bahwa mereka sudah hamil sehingga terlambat untuk datang memeriksakan diri. Selain itu, beberapa responden juga merasa sudah memiliki pengalaman pada kehamilan sebelumnya sehingga merasa tidak perlu untuk rutin datang memeriksakan kehamilan. Adapula responden lain yang tidak mengikuti asuhan antenatal sesuai standar mengakui bahwa dirinya sebenarnya telah mengetahui mengenai kehamilannya pada usia kehamilan trimester I, namun karena responden merasa tidak ada keluhan dan masalah terkait kehamilannya sehingga memutuskan untuk tidak melakukan pemeriksaan pada usia kehamilan muda.

Ternyata beberapa alasan inilah yang membuat masih adanya ibu hamil yang belum mengikuti asuhan antenatal sesuai standar di Puskesmas Somba Opu, Kabupaten Gowa. Ke semua alasan ini berakar pada kurangnya pemahaman masyarakat tentang pentingnya pemeriksaan kehamilan bagi ibu hamil dan juga janinnya sendiri.

Distribusi tingkat pendidikan responden di Puskesmas Somba Opu, Kabupaten Gowa menunjukkan sebagian besar memiliki tingkat pendidikan yang cukup yang telah menyelesaikan program pemerintah wajib belajar 9 tahun sebanyak 47 responden $(53.4 \%)$.
Pendidikan penting karena merupakan dasar dari mengertinya orang dalam hal menerima informasi. Pendidikan juga berperan penting dalam pembentukan kecerdasan manusia maupun perubahan tingkah lakunya. Pendidikan juga berarti bimbingan yang diberikan seseorang kepada orang lain terhadap sesuatu hal agar mereka dapat memahami. Tidak dapat dipungkiri bahwa semakin tinggi pendidikan seseorang maka semakin mudah pula mereka menerima informasi. Pada akhirnya banyak pula pengetahuan yang dimilikinya. Sebaliknya jika seseorang memiliki tingkat pendidikan yang kurang maka akan menghambat perkembangan sikap seseorang terhadap penerimaan informasi. ${ }^{9}$

Tabel 2 merupakan hasil penelitian distribusi tingkat pendidikan dan analisis hubungan tingkat pendidikan dengan kunjungan asuhan antenatal di Puskesmas Somba Opu. Hasil analisis statistik $(\mathrm{p}=0.037)$ menunjukkan bahwa ada hubungan tingkat pendidikan cukup dengan kunjungan asuhan antenatal di Puskesmas Somba Opu, Kabupaten Gowa, dengan kekuatan korelasi sebesar $\varphi=0,247$. Hal ini berarti terdapat hubungan lemah antara tingkat pendidikan cukup dengan kunjungan asuhan antenatal di Puskesmas Somba Opu, Kabupaten Gowa dan memberikan kontribusi sebesar $24.7 \%$ 
terhadap kesesuaian kunjungan asuhan antenatal yang dilakukan ibu.

Penelitian ini mendapatkan hasil yang juga sejalan dengan penelitian yang dilakukan (Lumempouw, Pelealu, \& Maramis, 2015) di Puskesmas Teling Atas, Manado yang menemukan bahwa terdapat hubungan antara tingkat pendidikan ibu dengan kunjungan antenatal care. ${ }^{10}$

Penelitian ini juga sesuai dengan penelitian yang telah dilakukan sebelumnya dimana didapatkan bahwa tingkat pendidikan ibu hamil risiko tinggi merupakan salah satu faktor yang berhubungan dengan peningkatan pengetahuan sehingga mendorong perilaku ANC pada ibu hamil. ${ }^{9}$

Menurut Rohan dan Siyoto (2013) bahwa tingkat pendidikan sangat mempengaruhi seseorang untuk bertindak dan mencari penyebab serta solusi dalam hidupnya. Orang yang berpendidikan tinggi biasanya lebih sering bertindak lebih rasional. Oleh karena itu orang yang berpendidikan akan lebih mudah menerima gagasan baru. ${ }^{10}$

\section{KESIMPULAN}

Berdasarkan hasil penelitian ini ditemukan bahwa terdapat hubungan signifikan antara tingkat pendidikan ibu hamil dengan kesesuaian kunjungan asuhan antenatal (ANC) berdasarkan keikutsertaannya di Puskesmas Somba
Opu Kabupaten Gowa, Sulawesi Selatan tahun 2016, dengan kekuatan hubungan lemah.

Peneliti merasa perlu untuk meningkatkan frekuensi penyuluhan dan pemberian informasi oleh pihak Puskesmas Somba Opu, Kabupaten Gowa kepada ibu hamil mengenai manfaat dari asuhan antenatal berupa pemeriksaan kehamilan, baik secara individu maupun secara kelompok. Disarankan bagi Pemerintah untuk terus melanjutkan penggalakan pendidikan wajib 12 tahun agar lebih meningkatkan pemahaman diri mengenai pentingnya mengikuti asuhan antenatal (ANC) secara teratur bagi ibu hamil.

Penelitian ini merupakan penelitian cross sectional study. Pada desain ini, semua variabel diukur pada saat yang sama. Dengan demikian, desain ini tidak dapat memastikan hubungan temporal (pengaruh waktu) antara tiap faktor terutama variabel kelompok umur saat kehamilan pertama dan yang berisiko dengan ibu hamil dalam mengikuti asuhan antenatal. Perlu dilakukan penelitian lebih lanjut dengan menggunakan rancangan case control study.

Karena jumlah responden yang sedikit, akibat adanya responden yang tidak nampak bersemangat ataupun menolak dalam menjawab pertanyaan karena terlalu banyak pertanyaan serta tidak sabar dalam menunggu antrian 
pemeriksaan kehamilan, maka hasil data yang diperoleh tidak bisa maksimal.

\section{DAFTAR PUSTAKA}

1. WHO, 2016. Maternal Mortality. [Online] Available at: http://www.who.int/mediacentre/facts heets/fs348/en/ [Accessed 22 January 2017].

2. Dinas Kesehatan Kabupaten Gowa, 2014. Profil Kesehatan Kabupaten Gowa Tahun 2014. [Online] Available at:

http://www.depkes.go.id/resources/do wnload/profil/PROFIL_KAB_KOTA 2014/7306_Sulsel_Kab_Gowa_2014.p df [Accessed 28 Sept 2016].

3. UNICEF Indonesia, 2012. Ringkasan Kajian Kesehatan Ibu dan Anak. [Online]

Available at: https://www.unicef.org/indonesia/id/A 5 -

B_Ringkasan_Kajian_Kesehatan_RE V.pdf [Accessed 21 January 2017].

4. Dinas Kesehatan Provinsi Sulawesi Selatan, 2014. Profil Kesehatan Provinsi Sulawesi Selatan Tahun 2014. [Online] Available at: http://dinkes.sulselprov.go.id/files_do wnload/Data2014.pdf [Accessed 28 Nov 2016].

\section{DAFTAR TABEL}

Tabel 1. Karakteristik Responden di Puskesmas Somba Opu, Kabupaten Gowa tahun 2016

\begin{tabular}{rcc}
\hline Variabel & $\mathbf{n}(\mathbf{8 8})$ & \% \\
\hline Kelompok Umur Ibu (Tahun) & & \\
$20-24$ & 37 & 42.0 \\
$25-29$ & 27 & 30.7 \\
$30-34$ & 16 & 18.2 \\
$35-39$ & 7 & 8.0 \\
$40-44$ & 1 & 1.1
\end{tabular}




\begin{tabular}{|c|c|c|}
\hline \multicolumn{3}{|l|}{ Usia Kehamilan } \\
\hline Trimester I & 20 & 22.7 \\
\hline Trimester II & 33 & 37.5 \\
\hline Trimester III & 35 & 39.8 \\
\hline \multicolumn{3}{|l|}{ Paritas } \\
\hline 0 & 21 & 23.9 \\
\hline 1 & 27 & 30.7 \\
\hline 2 & 26 & 29.5 \\
\hline 3 & 13 & 14.8 \\
\hline 4 & 1 & 1.1 \\
\hline \multicolumn{3}{|l|}{ Tingkat Pendidikan Ibu } \\
\hline Tidak/Belum Pernah Sekolah & 1 & 1.1 \\
\hline Tidak/Belum Tamat SD & 3 & 3.4 \\
\hline $\mathrm{SD} / \mathrm{MI} / \mathrm{setara}$ & 17 & 19.3 \\
\hline SMP/MTS/setara & 20 & 22.7 \\
\hline SMA/MA/sederajat & 31 & 35.2 \\
\hline Akademi/Diploma & 9 & 10.2 \\
\hline Universitas & 7 & 8.0 \\
\hline \multicolumn{3}{|l|}{ Pekerjaan Ibu } \\
\hline Tidak Bekerja/IRT & 64 & 72.7 \\
\hline Petani/Berkebun/Peternak/Penambak & 1 & 1.1 \\
\hline Pedagang & 8 & 9.1 \\
\hline Karyawan/Wiraswasta & 14 & 15.9 \\
\hline Pegawai Negeri Sipil (PNS) & 1 & 1.1 \\
\hline
\end{tabular}

Sumber: Data Primer, 2016

Tabel 2. Hubungan Tingkat Pendidikan dengan Kunjungan Asuhan Antenatal di Puskesmas Somba Opu, Kabupaten Gowa Tahun 2016

\begin{tabular}{|c|c|c|c|c|c|c|c|}
\hline \multirow{3}{*}{ Tingkat Pendidikan } & \multicolumn{4}{|c|}{$\begin{array}{c}\text { Kunjungan Asuhan } \\
\text { Antenatal (ANC) }\end{array}$} & \multirow{3}{*}{$\mathbf{n}$} & \multirow{3}{*}{$\%$} & \multirow{3}{*}{$\begin{array}{l}\text { Hasil Uji } \\
\text { Statistik }\end{array}$} \\
\hline & \multicolumn{2}{|c|}{$\begin{array}{l}\text { Sesuai } \\
\text { Standar }\end{array}$} & \multicolumn{2}{|c|}{$\begin{array}{c}\text { Tidak } \\
\text { Sesuai } \\
\text { Standar }\end{array}$} & & & \\
\hline & $\mathbf{n}$ & $\%$ & $\mathbf{n}$ & $\%$ & & & \\
\hline Pendidikan Kurang & 33 & 37.5 & 8 & 9.1 & 41 & 46.6 & $X^{2}=5.359$ \\
\hline Pendidikan Cukup & 27 & 30.7 & 20 & 22.7 & 47 & 53.4 & $\mathrm{p}=0.037$ \\
\hline Jumlah & 60 & 68.2 & 28 & 31.8 & 88 & 100 & $\varphi=0.247$ \\
\hline
\end{tabular}

Tabel 3. Analisa Multivariat dengan Uji Regresi Logistik

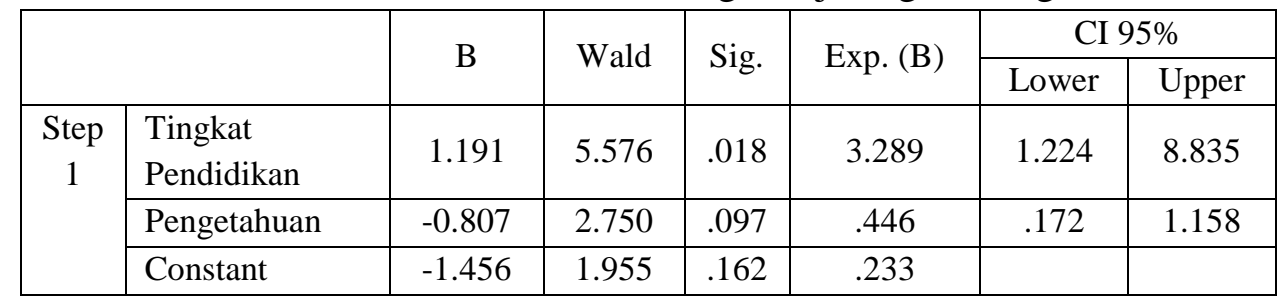

